\title{
Provision of community pharmacy services during the first wave of COVID-19 pandemic in Estonia - experiences and future implications
}

\author{
Kristiina Sepp ${ }^{1, *}$, Kadi Lubi ${ }^{2}$, Hedvig Rass ${ }^{3}$, and Daisy Volmer ${ }^{1}$ \\ ${ }^{1}$ University of Tartu, Institute of Pharmacy, Faculty of Medicines, Tartu, Estonia \\ ${ }^{2}$ Tallinn University of Technology, E-medicine Centre, Department of Health Technologies, Tallinn, \\ Estonia \\ ${ }^{3}$ Tartu Sõbra Apteek, Tartu, Estonia
}

\begin{abstract}
The spread of COVID-19 outbreak in 2020 had significant impact on the functioning of the existing healthcare system and required fast adaption to new circumstances for continuing with daily practices. Community pharmacists shared responsibility of ensuring supply of medicines and medical devices, educating people on health related issues, providing pharmaceutical care etc. The aim of this study was to understand how the provision of community pharmacy services changed during the first wave of COVID-19 pandemic in spring of 2020 in Estonia. Qualitative in-depth semi-structured interviews were conducted. Recorded interviews with community pharmacists $(n=21)$ and experts $(n=10)$ were transcribed verbatim and a systematic text condensation method for textual content analysis was performed. The findings indicated that a number of changes took place in provision of community pharmacy services to assure continuity in providing high-quality pharmacy services in crisis, including addressing difficulties in the supply of medicines; at the same time, to acquire new knowledge for counselling health related topics and personal protective equipment, and to provide psychological support to people in stress. Pandemic had an impact on the content and structure of traditional community pharmacy services in Estonia. The need for expanded professional role of pharmacists was clearly expressed in an emergency situation.
\end{abstract}

\section{Introduction}

Community pharmacists are the most accessible healthcare professionals and often as the first point of contact for patients within healthcare system [1,2]. They are specialists of medicines, counselling the patients or other healthcare professionals and compounding medicines, but also support patient's self-care and general wellbeing. The extent of community pharmacy practice differs considerably within countries $[3,4]$. In some countries the professional competencies of pharmacists are underused, in other countries, in contrast, the role of community pharmacists has evolved and in addition to traditional services, extended services, e.g., vaccination, point-of-care testing and health screening are offered. The role of pharmacists should be further expanded, as general phenomena such as the aging population and the lack of

\footnotetext{
*Corresponding author: kristiina.sepp@ut.ee
} 
a professional workforce and resources in healthcare are well-known problems around the world $[2,4]$.

Studies have shown that community pharmacists can reduce the workload of general practitioners, ensuring the quality of care and patient satisfaction [4-6].

In Estonia, community pharmacists offer traditional services such as compounding and dispensing of medicines and providing drug information to pharmacy customers. Extended services are mostly profession-driven initiatives and not integrated into healthcare system [7]. Mostly point-of-care testing (e.g., measuring blood pressure, blood glucose) is provided, but recently some extended services have been piloted: in 2018 pharmacy-based vaccination service and in 2019-20 medication use review service [8,9]. The existing pharmacy network consists of 485 community pharmacy units (01.01.2021), where 803 pharmacists and 652 assistant pharmacists are employed [7,10]. For 99\% inhabitants of Estonia the community pharmacies are 15 minutes car-drive away and also four online-pharmacies operate $[11,12]$. According to a study commissioned by the Ministry of Social Affairs, 94\% of the population visit a community pharmacy at least once in half a year [13].

The spread of COVID-19 had significant impact on the functioning of the existing healthcare systems. It required fast adaption to new circumstances for continuing with daily practices, i.e., delivering of preventive care and managing chronic patients. They also include treatment of people with severe conditions due to COVID-19. During COVID-19 pandemic, community pharmacists, working alongside with other frontline healthcare professionals, had to secure the availability, accessibility, and quality of the service to maintain the health of the population. Community pharmacists shared responsibility of ensuring supply of medicines and medical devices (e.g., masks), educating people, providing preventative care, etc [14]. Various countries engaged community pharmacists even more to tackle with COVID-19 better and to ease the demand for the healthcare services. In Austria, Canada, Ireland, SouthAfrica, Portugal, the United States and France, pharmacists have been allowed to extend prescriptions and, in some cases, also prescribe certain medicines to ensure continuity of treatment $[4,15-17]$. In addition, community pharmacists contribute in various ways to COVID19 vaccination, also providing rapid antigen tests for COVID-19 and being first port of call for common ailments [16].

The aim of this study was to understand how the provision of community pharmacy services changed during the first wave of COVID-19 pandemic in spring 2020 in Estonia.

\section{Material and methods}

In Estonia, the COVID-19 pandemic related emergency entered in force and followed major nationwide lockdown at the beginning of March 2020 with restrictions to access of healthcare services. Only remote consultations with general practitioners via phone or other telecommunication tools were possible and other ambulatory care visits were stopped. However, community pharmacies continued the daily practice and face-to-face contacts with the need to adjust with unexpected and sudden new rules in service provision.

\subsection{Study design and sample}

Qualitative in-depth semi-structured interviews were used. The interview guide consisted of 3 themes (the general organization of pharmacy service provision, the quality of provided pharmacy services and the role of pharmacy prior to and during the COVID-19 pandemic) with 18 open-ended questions helping to define the areas to be explored, but also allowed 
following interesting thematic topics that participants brought out. The interviews were performed among 21 community pharmacists, 3 hospital pharmacists and 10 different stakeholders (named experts in this study) of healthcare and pharmaceutical sector. Purposeful sampling was used with regard to gain representation within different stakeholder groups [18]. Data review and analysis were made in conjunction with data collection. It helped to assess whether data saturation was achieved and when it was acceptable to stop data collection.

\subsection{Data collection}

Three different persons conducted the interviews individually through telecommunications tools, i.e., Skype, Skype Business, Teams, Zoom and a phone call. The duration of interviews varied from 20 to 110 minutes. All conducted interviews were audio-recorded and transcribed verbatim. After transcription, all audio files were deleted. Each interview was assigned a code, corresponding to Estonian word and containing the interview's number, identifier by the speciality (pharmacist - A, hospital pharmacist - HA, and expert - E), identifier according to the size of the municipality where the pharmacy was located (bigger city - SL, smaller city VL, countryside pharmacy - MA) and its type (situated in shopping centre - 1, in healthcare centre -2 , or located separately -3 ) (Table 1).

Table 1. Distribution of study participants.

\begin{tabular}{|c|c|c|c|c|c|c|c|c|c|c|}
\hline & Total & \multicolumn{3}{|c|}{ Big city } & \multicolumn{3}{|c|}{ Small city } & \multicolumn{3}{|c|}{ Rural area } \\
\hline \multirow{4}{*}{$\begin{array}{l}\text { Community } \\
\text { pharmacists }\end{array}$} & \multirow{4}{*}{21} & \multicolumn{3}{|c|}{13} & \multicolumn{3}{|c|}{5} & \multicolumn{3}{|c|}{3} \\
\hline & & \multicolumn{9}{|c|}{ Pharmacy type } \\
\hline & & $1 *$ & $2 *$ & 3* & $1 *$ & 2* & 3* & 1* & $2 *$ & $3 *$ \\
\hline & & 7 & 2 & 4 & 1 & 0 & 4 & 1 & 1 & 1 \\
\hline \multirow{2}{*}{ Experts } & \multirow{2}{*}{10} & \multicolumn{3}{|c|}{$\begin{array}{c}\text { Other healthcare } \\
\text { professionals }\end{array}$} & \multicolumn{3}{|c|}{$\begin{array}{c}\text { State } \\
\text { representatives }\end{array}$} & \multicolumn{3}{|c|}{$\begin{array}{c}\text { Other pharmacy } \\
\text { stakeholders }\end{array}$} \\
\hline & & \multicolumn{3}{|c|}{2} & \multicolumn{3}{|c|}{4} & \multicolumn{3}{|c|}{4} \\
\hline $\begin{array}{c}\text { Hospital } \\
\text { pharmacists }\end{array}$ & 3 & \multicolumn{3}{|c|}{2} & \multicolumn{3}{|c|}{1} & & & \\
\hline
\end{tabular}

*1- shopping centre, 2- healthcare centre, 3-pharmacy with separate location.

\subsection{Data analysis}

For data analysis, a systematic text condensation method developed by Malterud was used [19]. The method is descriptive and explorative for the thematic analysis of different types of qualitative data. This method outlines the experience of the participants as expressed by them instead of examining possible underlying meaning of what was said. Systematic text condensation method consists of four comparable steps of analysis:

(1) total impression - understanding of the scope of topic;

(2) identifying and sorting meaning units - organizing the data through coding the text, i.e., a quote or a sentence that are relevant to study question;

(3) condensation - from code to meaning, one by one examination of meaning units to get a precise understanding of the content of every unit; 
(4) - information received from meaning units is developed consistent statement synthesizing [19].

Data analysis was carried out separately for condensed information from experts and community pharmacists. Responses of hospital pharmacists were excluded as this research focused on changes in community pharmacy practice during pandemic. In the results section developed consistent statements are presented as an analytical text, and it is illustrated with participants' quotes.

\subsection{Ethical considerations}

The research aimed to understand professional opinions and perception about the change of provision of community pharmacy service during COVID-19 first outbreak without any focus on personal data. All the participants were introduced to the aims and methods of the research, including the participants' right to withdraw their participation at any time. In addition, participants were notified that the audio files with their interviews would be deleted immediately after verbatim transcription and regular and appropriate oversight for the carriedout research takes place. Written informed consent from participants was gathered prior interviews. The researchers followed the principles of medical ethics and the local Personal Data Protection Act [20-22].

\section{Results and discussion}

In Estonia, the COVID-19 pandemic affected the operation of healthcare system including community pharmacies. A number of changes took place in service provision- to assure continuity of high-quality pharmacy services in crisis, including addressing difficulties in the supply of medicines; at the same time, to acquire new knowledge for counselling health and personal protective equipment and to provide psychological support to people in stress about COVID-19.

\section{Statement 1. Community pharmacies provided convenient access to patient care and medicines}

The fast and convenient access to the patient care due to the location and opening hours of community pharmacies is well known from the pre-COVID-19 period but has not been well recognized by the other healthcare stakeholders in Estonia [7]. According to pharmacists in this study, the pandemic demonstrated potential of community pharmacies as healthcare institutions to offer a wide range of consultations about health and medicines while the other healthcare services were unavailable or with limited access.

"It was such a situation that these family doctors and hospitals have stopped scheduled appointments, then pharmacists were like the most accessible primary healthcare professionals." (29_A_VL_1)

The collaboration with other healthcare professionals even improved.

"Since they (the doctors) did not see the patient and we actually saw, they (the doctors) listened to us (pharmacists) more." (27_A_SL_3)

Experts more often noted that the main purpose of the pharmacy service is to ensure the availability of medicines to the patient and the care function seemed to be secondary as remote contact with general practitioners (GP) was available.

"You could still have a telephone consultation with a family doctor and, secondly, the same family doctor's advice line... the volume of calls was greatly increased during the crisis, so that people still used this service very much." (02_E) 
On the other hand, the experts recognized fast and flexible reorientation of pharmacists in assuring safe conditions for patients and pharmacy staff to be able to operate on regular basis.

"After all, pharmacies also needed to quickly change their work organization, both to protect their employees and to protect patients /.../in my opinion, pharmacies and pharmacists very calmly, professionally, and quickly reoriented, work organization was changed." (15_E)

Internationally, the access to patient care and medicines at community pharmacies during COVID-19 was similarly described as it was highlighted by community pharmacists in this study $[23,24]$. In many European countries, community pharmacists were the first contacts for health-related and self-protection against COVID-19 advice, and provided consultation related to social aspects of corona virus $[5,16]$.

Overall, community pharmacies in Estonia were well accessible for patient care and supply of medicines during a corona pandemic. Pharmacies, being one of the few providers of primary contact in primary health care, were also important partners for other healthcare professionals. This could serve as a model to introduce efficient integration of community pharmacy sector into healthcare system of Estonia.

\section{Statement 2. COVID-19 has had an impact on the content and form of dispensing and counselling of medicines}

According to the responded pharmacists, the counselling process shortened and became more compact.

"In a counselling process, we had to communicate any information very compactly and people often came with very specific wishes." (19_A_SL_3)

The changed pharmacy environment, as well, influenced the service provision: different movement restrictions, glass barriers on the counter and rules on the walls. All this affected the counselling process and behaviour of pharmacists as well as pharmacy customers. While pharmacists normally advised patients in the sales area, this was limited during a pandemic.

Furthermore, privacy in community pharmacies got a new meaning.

"After all, a pharmacy is not such a private place where you can always talk about your very personal things for a little longer, because that is why patients often prefer to see a doctor first and talk about their personal concerns and then ask about it." (19_A_SL_3)

During COVID-19 keeping distance was strictly required. It allowed community pharmacists to provide more person-centred care (although with more limited counselling time than in normal situations) and create an environment where patients felt more confident to speak openly about their health-related concerns. Only a few community pharmacies in Estonia have a separate counselling room [25]. In many other countries private consultation rooms in community pharmacies are a norm, in addition, it supports the provision of other extended services, e.g., vaccination and medication use review [26]. Providing a supportive and accommodating person-centred care environment influences the experience of the patients, but also improving health outcomes and safety aspects of care [27].

COVID-19 has changed the use of info-technology and remote services. E-pharmacies became very popular among the population and in 2020-2021 three new online-pharmacies were opened in Estonia [12].

"Just as all e-commerce rose, so did the actual provision of pharmacy services over the internet, this corona period certainly gave it some impetus.” (10_E)

To better respond to COVID-19, innovative and extended methods of practice will be needed to ensure the access to medicines and pharmaceutical care during emergency [5]. However, pharmacists asked whether online pharmacies are the best solutions for receiving medicines. 
"This e-commerce is one that will certainly stay, which will affect us a great deal. The question is whether this medication should have that place there. But I think it definitely became a new habit for many.” (25_A_SL_3)

Nevertheless, community pharmacy service in Estonia has undergone digital transformation with use of different e-tools for dispensing and counselling of medicines including assessment of potential drug-drug interaction [7].

Ultimately, pandemic restrictions affected both the conditions and the content of the service. Patient counselling became shorter and more structured. Using the same approach in normal circumstances could speed up the counselling process, but not at the expense of its quality. Organizing private counselling at community pharmacies in Estonia could be one of the first priorities in the future, and, in this connection, some useful tips can be taken from the measures already were in use during pandemic. The pandemic boosted e-pharmacies. In the future, it will be important to combine distance sale of medicines and traditional pharmacy services so that the patient benefits the most from using described combination.

\section{Statement 3. Community pharmacists became a relevant source of health-related issues for the public}

During pandemic, the community pharmacies played a vital role in supporting and sharing relevant health information to people in local communities, starting with information about self-protection against COVID-19, as well as social and other person's wellbeing concerns. Community pharmacists became a trusted source for people to manage with new circumstances and to get reliable information. Public expectations towards community pharmacists required continuous self-improvement of knowledge and search for evidence-based information.

"The expectations toward pharmacists have certainly increased, therefore your knowledge has to be up-to-date, and you should have the ability to share the knowledge with others and then actually analyse it before doing that." (25_A_SL_3)

Experts provided controversial feedback. Some of them did not see the important role of pharmacists in informing the public about COVID-19 aspects, since there were several other sources people could use.

"Whether they go like asking the pharmacist for advice on corona. I think this information is so much anywhere, that it is questionable if someone wants to go to the pharmacy to ask about this.” (07_E)

On the other hand, they agreed with poor crisis communication regarding COVID-19 to the public. In described circumstances, pharmacists were considered a reliable source of information.

"Everyone gave instructions to everyone, but still people came to the pharmacy and this mask was under here (under the chin). How to use the masks, because really in some cases he practically had eyes covered with it - pharmacists had to advise and give directions." (23_A_MA_2)

Educating the public on infection control and preventive measures to decrease the spread of the virus was seen as key activity of pharmacists during COVID-19.

On a daily basis mass media produces often dramatic news sowing fear and panic. Tsao et al. outlined that social media can have a crucial role in disseminating health information and tackling infodemics and misinformation about COVID-19 [28,29]. Therefore, it is expected that healthcare professionals are up to date with evidence based and reliable information. Pharmacists are well prepared to broaden the community's horizons about possible safeguards and medications providing evidence-based information starting from the most recent prevention and treatment of the coronavirus, and the instructions of the relevant scientific literature $[30,31]$. 
In conclusion, based on their professional competency, knowledge and accessibility, community pharmacists are capable to provide adequate health-related information and care in communities. Therefore, the involvement of pharmacists in tackling public health challenges by expanding their counselling competencies to other areas of health care could be seen as a valuable asset.

\section{Statement 4. Community pharmacists demonstrated expertise on support of rational use of medicines}

The medication shortages worldwide have been increasing in recent years and has been described as a healthcare crisis in itself [32,33]. During COVID-19 pandemic, the situation in many countries deteriorated further [34]. Similarly, in other countries, new dispensing rules eased the stockpiling of medicines and other supplies in Estonia as well, mainly through limited dispensing quantities of prescription and over-the-counter medicines.

"When we managed to get twenty originals, then we really distributed these twenty originals to our twenty patients." (32_A_SL_2)

Experts also brought out the expertise of pharmacists in supporting the rational use of medicines and sufficient stocks of medicinal products at home.

"I would trust our pharmacists on this site even more, who can justify to people how much you really need to stock up and what is reasonable and what quantities should you buy at home, when ten tablets and when one hundred tablets." (03_E)

Generic substitution of medicines increased despite the fact that pharmacists, even during the pre-COVID-19 period, were obliged to recommend always the most affordable medicine to the patient.

Even "when a patient wanted to get the original medicine, there was only a generic medicine." (18_A_SL_1)

Under the new circumstances i.e., social distancing and limited movement, more open attitude from patients towards generic medicines was noticed, but also pharmacists provided additional consultation about dispensing limitations and availability of medicines. Many countries have expanded the scope of a community pharmacist to ensure the continuity of care and timely access to medicines: prolonging prescriptions for chronic patients, prescribing for patients in the event of a health emergency etc [15]. Described initiatives enable to use professional competencies of pharmacists and ease the workload of GP-s. In Germany, pharmacists have been allowed to change the amount and the strength of a medicine, or even dispense another, but similar medicine [35]. In Estonia, the community pharmacists were not given a wider professional role during COVID-19 pandemic and in many cases, they had to face patients who did not have a prescription for their medicine and contact with the prescriber was complicated.

"Our patients said, they just cannot reach their GP, but in such cases, we cannot help them if it is a prescription drug, we cannot dispense it without a prescription, it is absolutely impossible.” (29_A_VL_1)

In the recent years, the development of Community Pharmacy Service Quality Guidelines (CPSQG) has supported the development and standardization of pharmacy services in order to expand pharmacists' role in the primary health care system in Estonia [25]. It has been claimed that future developments allowing pharmacists to practice to the full extent of their competencies, to boost the health workforce capacity, to tackle the healthcare challenges including future pandemic crises would be vital [4]. Therefore, it is also important for pharmacists in Estonia to be able to use all their professional expertise about medicines in the 
future. The pandemic highlighted the urgent need for prescribing of medicines and following international experience, described problems could be solved by a pharmacist.

\section{Statement 5. Provision of psychological and social support at community pharmacy was essential for the patient}

The pandemic showed pharmacists in a new light, and for some people they even became heroes. The lack of adequate information or constantly changed information, limited access to services and state institutions or even not seeing elderly family members created additional panic and psychological distress.

"During this pandemic, the role of pharmacist was so special, because people had nowhere to go. Those who were completely alone with their problems, and we were available, and not only about issues related to medicines.” (28_A_SL_1)

People faced with new realities affecting their mental, as well as physical health. People were looking for human contact and found it in pharmacy.

"This human contact. It is very important and that is what probably brings this person back to the pharmacy in the end .... as feedback from our patients, they have said that in this respect, the pharmacy has been the stable point that has remained as rescue, ambulance, police. So, whoever wanted their personal pharmaceutical advice, or people who just needed social support, in such cases the pharmacist was actually very important." (25_A_SL_3)

Experts also highlighted the pharmacists "important role for the public during pandemic.

"What the added value of this thing (community pharmacists) is that there is this professionalism and communication skills, the ability to calm down, which was actually quite well, tangible during COVID-19." (09_E)

Community pharmacists can be a key player in fighting with mental illnesses and support people within communities. People will continue to visit community pharmacists as a trusted source of advice, and therefore it is critical that the pharmacy professionals are trained and well-equipped to support people's wellbeing and mental health better [36,37].

Overall, the pandemic highlighted another important role of pharmacists - psychological support for the patient when needed. It would broaden the ability to support people with psychosocial needs arising from non-medical determinants and ultimately reach to people who have limited access to mental health services. However, all above described activities would require stronger link between pharmacies and both the health and social systems.

\section{Conclusion}

The COVID-19 pandemic highlighted the vital role of community pharmacies in healthcare. Despite the fact that the emergency partially hampered the functioning of primary health care services, community pharmacies continued regular operation, providing patients with care and access to medicines. Pandemic had impact on the content and structure of traditional community pharmacy services. The use of e-pharmacy services increased significantly. The need to expand pharmacists' professional roles as a prescriber, health counsellor, as well as a psychologist and social worker, was clearly expressed in an emergency. This experience could be used as a basis for public discussions in developing the extended professional role of pharmacists and supporting more effective collaboration with other healthcare specialists and also exploited in the potential new pandemic situation.

\section{References}

[1] C.O. Agomo, J Pharmaceut Health Serv Res 3, 25-33 (2012) 
[2] Pharmaceutical Group of European Union, Pharmacy 2030: A vision for Community Pharmacy in Europe, Available online: https://www.pgeu.eu/wpcontent/uploads/2019/04/Pharmacy-2030_-A-Vision-for-Community-Pharmacy-inEurope.pdf (accessed 12 June 2021)

[3] World Health Organization. Regional Office for Europe. The legal and regulatory framework for community pharmacies in the WHO European Region. World Health Organization. Regional Office for Europe (2019)

[4] OECD. Realising the Potential of Primary Health Care, OECD Health Policy Studies. OECD Publishing (2020)

[5] C.A. Cadogan, M.H. Carmel, Res Social Adm Pharm 17, 1 (2021)

[6] L. Green, S. Savin, Y. Lu, Health Aff 32, 1 (2013)

[7] K. Sepp, A. Tuula, V. Bobrova, D. Volmer, Pharm Pract (Granada) 19, 2404 (2021)

[8] K. Sepp, C. Kukk, A. Cavaco, D. Volmer, Expert Rev Vaccines 19, 983-990 (2020)

[9] A.Tuula, L.Randmäe, D.Volmer, Perearst 155, 18-21 (2020)

[10] Ravimiamet [State Agency of Medicines], Apteegi statistika [Pharmacy statistics], Available online: https://sam.ee/apteegistatistika?group=5 (accessed 5 June 2021)

[11] Sotsiaalministeerium [Ministry of Social Affairs]. Üldapteekide geograafiline paiknemine ning selle vajaduse hindamine [Geographical location of general pharmacies and assessment of its need], Sotsiaalministeerium (2014), Available online: https://www.sm.ee/sites/default/files/content-editors/eesmargid $\_j a \_$tegevused/Tervis/ Ravimid/ulevaade $\_$apteekide $\backslash$ geograafilisest $\backslash$ paiknemisest $\backslash \_l o p p v e r s i o o n . p d f$ (accessed 10 June 2021)

[12] Ravimiamet [State Agency of Medicines], Interneti apteegid [Online Pharmacies], Available online: https://ravimiamet.ee/en/node/7041 (accessed 5 June 2021)

[13] Kanter Emor, Apteegi külastajate kogemused ja ootused apteegiteenuse kvaliteedile, Sotsiaalministeerium (2021)

[14] International Pharmaceutical Federation (FIP Health Advisory, Coronavirus 2019n CoV Outbreak, (2020) Available online: www.fip.org/files/content/priority-areas/ coronavirus/Coronavirus-guidance-update-ENGLISH.pdf (accessed 10 June 2021)

[15] P. Merks, M. Jakubowska, E. Drelich E, et al., Res Social Adm Pharm 17, 1807-1812 (2021)

[16] Pharmaceutical Group of European Union, Position Paper on the Role of Community Pharmacists in COVID-19 - Lessons Learned from the Pandemic, Available online: https://www.pgeu.eu/wp-content/uploads/2020/03/PGEU-Position-Paperon-on-the-Lessons-Learned-from-COVID-19-ONLINE.pdf (accessed 10 June 2021)

[17] Medical Brief, Act amendment allows extension of expiring prescriptions from 6 to 12 months, (2020), Available online: https://www.medicalbrief.co.za/archives/actamendment-allows-extension-of-expiring-prescriptions-from-6-to-12-months/ (accessed 4 June 2021)

[18] G.S. Guest, E.E. Namey, M.L. Mitchell, Collecting Qualitative Data: A Field Manual for Applied Research (Thousand Oaks, CA: Sage Publications Inc., 2012)

[19] K. Malterud, J. Public Health 40, 795-805 (2012)

[20] T.L. Beauchamp, The "Four Principles "Approach to Health Care Ethics, Principles of Health Care Ethics (Chichester: John Wiley \& Sons Ltd, 2015)

[21] World Medical Association, WMA Declaration of Helsinki - Ethical Principles for Medical Research Involving Human Subjects, (2013), Available online: https://www.wma.net/policies-post/wma-declaration-of-helsinki-ethical-principlesfor-medical-research-involving-human-subjects/ 
[22] Personal Data Protection Act, Estonia: RiigiTeataja (2019), Available online: https://www.riigiteataja.ee/en/eli/523012019001/consolide

[23] C.Oi Lam Ung, Res Social Adm 16, 583-586 (2020)

[24] N. AlMazrouei, R.M. Ibrahim, A.Z. AlMeslamani, D.H. Abdel-Qader, A. ShabanSadeq, O.M. Ibrahim, Int J Pharm Pract 29, 137-144 (2021)

[25] K. Sepp, A. Cavaco, A. Raal, D. Volmer, Healthc (Amst) 9, 804 (2021)

[26] P. Kruus, G. Paat-Ahi, Kaasaegse apteegiteenuse roll esmatasandi tervishoiu osana Eesti tervishoiusüsteemi jätkusuutlikkuse tagamisel [The role of modern pharmacy services as part of primary health care in ensuring the sustainability of the Estonian health care system] (2013)

[27] L.A.H. Kvæl, A. Bergland, BMC Health Serv Res 21, 180 (2021)

[28] S.F. Tsao, H. Chen, T. Tisseverasinghe, M. Yang Yang, L.Li, Z.A.Butt, Lancet Digit Health 3, 175-194 (2021)

[29] J. Thomas, G.M. Peterson, E. Walker, J.K. Christenson, M. Cowley, S. Kosari, K.E. Baby, M. Naunton, Clin Pharmacol Ther 104, 1059-1061 (2018)

[30] D.A. Erku, et al., Res Social Adm Pharm 17, 1954-1963 (2020)

[31] O.M. Al-Quteimat, A. M. Amer, Res Social Adm Pharm 17, 480-482 (2020)

[32] World Health Organization, Drug Information 30, 2 (2016), Available online: https://www.who.int/medicines/publications/druginformation/WHO_DI_302_Medicines.pdf?ua=1

[33] C.A. Cadogan, C.M. Hughes, Res Social Adm Pharm 17, 2032-2035 (2021)

[34] C.M. Bookwalter, US Pharm 46, 25-28 (2021)

[35] Deutsches Apotheken Portal. Dürfen wir während der Pandemie auch Arzneimittel der Substitutionsausschlussliste austauschen? (2020) Available online: https://www.deutschesapothekenportal.de/rezept-retax/apothekenfragenarchiv/vollstaendiger-beitrag/duerfen-wir-waehrend-der-pandemie-auch-arzneimittelder-substitutionsausschlussliste-austauschen/ (accessed on 21 June 2021)

[36] The Royal Pharmaceutical Society. The role of pharmacy in mental health and wellbeing. Available online: https://www.rpharms.com/recognition/all-our-campaigns/policya-z/pharmacy-in-mental-health-and-wellbeing (accessed on 25 June 2021)

[37] A.K. Mohiuddin, Sch J Psychol\&Behav Sci. 2, 219-223 (2019) 